\title{
Mobile payment, third-party payment platform entry and information sharing in supply chains
}

\author{
Xiaojun Fan $^{1} \cdot$ Wenyu Zhao ${ }^{1} \cdot$ Ting Zhang $^{1} \cdot$ Endian Yan $^{1}$
}

(c) Springer Science+Business Media, LLC, part of Springer Nature 2020

\begin{abstract}
With the development of information technology, increasing retailers cooperate with thirdparty payment platforms (3PPs) to provide mobile payment service for consumers. The entry of 3PPs into supply chains, not only changes the cash flow, but also decreases consumer price sensitivity and stimulates demand by facilitating credit consumptions. Moreover, information sharing becomes more feasible with the help of 3PPs. To study the impacts of 3PP entry, we build game-theoretic models in a supply chain consisting of a manufacturer, a retailer and a $3 \mathrm{PP}$, and derive the equilibrium in both the non-information sharing and information sharing cases. We show that the 3PP should make a reasonable commission rate which can lure the retailer to introduce the 3PP as well as maintain the 3PP's profitability. The 3PP entry allows the retailer to set a higher price without decreasing the demand. However, to seize all of the benefit of the 3PP entry, the first mover manufacturer increases the wholesale price to a large extent. As a result, the 3PP entry causes a win-lose situation for the manufacturer and the retailer. The supply chain can be better off from the 3PP entry if it can significantly decrease consumer price sensitivity or its fixed investment cost is low. Furthermore, we find that information sharing benefits the manufacturer and the 3PP but harms the retailer. While information sharing always decreases the expected profit for the supply chain without the $3 \mathrm{PP}$, it may increase that for the supply chain with the 3PP. To improve the supply chain profitability, we suggest to provide incentives for retailer information sharing if the $3 \mathrm{PP}$ can significantly decrease consumer price sensitivity (i.e., the proportion of the $3 \mathrm{PP}$ users is higher, the grace period of credit consumption is lower, or the cash opportunity cost is lower).
\end{abstract}

Keywords Mobile payment - Credit consumption · Third-party payment platform · Information sharing $\cdot$ Supply chain

Ting Zhang

tcheung@shu.edu.cn

1 Shanghai University, Shanghai, China 


\section{Introduction}

Mobile payment, which service is provided by third-party payment platforms (3PPs) such as Alipay, Wechat Pay and Jingdong Pay, is prevalent in retailing. With the service, consumers can conveniently make payments with cellphones by displaying their Quick Response (QR) codes for sellers to scan, or scanning the sellers' QR codes. Increasing customers use mobile payment in their daily consumption behaviors, such as supermarket shopping, and restaurant bills. Iresearch's reported that the transaction scale of mobile payment reached 110.4 trillion RMB in first half of 2019 in China. The COVID-19 pandemic in 2020 is a great challenge for the world. The virus can spread through contact, whereas cash transactions inevitably lead to contact and increase the likelihood of infection. Compared with contactless mobile payment, cash payment is "unhygienic". ${ }^{1}$ On 31 January 2020, the ministry of commerce and the national health commission of China jointly issued "credit card payment and various mobile payment methods are advocated". So far, mobile payment has been penetrated into all aspects of people's daily life in China. Some people even believe that China will enter a cashless era in the future.

Now, increasing retailers introduce 3PPs to provide mobile payment service for consumers, which can significantly affect supply chain operations. The 3PPs are typical bilateral service platforms which link buyers and sellers. The 3PPs can change cash flow in supply chains. In supply chains without 3PP, consumers pay directly to retailers. If 3PPs enters into supply chain, consumers can pay retailers indirectly via 3PPs, which charge commissions for payments and transfer the rest to the retailers (see Table 1 for illustrations of 3PP commission rates). Remarkably, 3PPs facilitate credit consumption for consumers. For example, Baitiao (of Jingdong pay) and Huabei (of Alipay) allow consumers to consume now and pay later. ${ }^{2}$ Credit consumption usually has a long period for repayment (Chen et al. 2018). The consumers can make interest-free repayment before the deadline. Thus, credit consumption provided by 3PPs can decrease consumer price sensitivity and stimulate demand. Moreover, as an information intermediary, 3PPs can effectively solve the problems caused by information asymmetry between buyers and sellers. Information sharing becomes more feasible with the help of 3PPs.

Motivated by the prevalence of mobile payment, we investigate the effects of the 3PP entry on supply chain operations and performances. We develop game-theoretic models in a single-manufacturer-and-single-retailer supply chain to which the 3PP may enter. The manufacturer sells a product to consumers through the retailer. The market potential is random, on which the supply chain members may have asymmetric information. If the retailer does not introduce the $3 \mathrm{PP}$, the consumers pay with cash. If the retailer introduces the 3PP, the consumers can use mobile payment, which facilitates credit consumption and decreases consumer price sensitivity. Nevertheless, the retailer has to pay commissions to the 3PP. We consider a multi-stage game: the manufacturer sets the wholesale price in Stage 1, the retailer sets the retail price in Stage 2, the 3PP sets the commission rate in Stage 3, the retailer decides on whether to introduce the 3PP or not in Stage 4. We derive the sub-game perfect equilibrium in both the non-information sharing and information sharing cases. The retailer which is closer to consumers generally has more market information than the manufacturer. In the meantime, the 3PP (such as Alipay and Wechat) can access the retailer's

\footnotetext{
${ }^{1}$ http://www.gov.cn/zhengce/zhengceku/2020-02/01/content_5473639.htm.

2 In Chinese, baitiao means "you can pay later" and Huabei means "just consume it".
} 
Table 1 3PPs and commission rates

\begin{tabular}{lllllll}
\hline $3 \mathrm{PP}$ & Alipay (\%) & Wechat $(\%)$ & $\begin{array}{l}\text { Jingdong pay } \\
(\%)\end{array}$ & $\begin{array}{l}\text { Baidu wallet } \\
(\%)\end{array}$ & Union pay (\%) & Yee pay (\%) \\
\hline $\begin{array}{l}\text { Commission } \\
\text { rate }\end{array}$ & 0.6 & 0.6 & 0.7 & 0.6 & 0.8 & 0.6 \\
\hline
\end{tabular}

payment information and use it to accurately forecast the market information with big data technology. Thus, both the retailer and 3PP can better forecast the market information than the manufacturer. In the non-information sharing case, the retailer and the 3PP do not share the information with the manufacturer. In the information sharing case, the retailer shares the information with the manufacturer, and thus all supply chain members have symmetric information.

To our best knowledge, our study is the first to analytically address the operations associated with mobile payment and 3PPs in supply chains. Specifically, our research questions are as follows.

1. What are the optimal decisions of the manufacturer, the retailer and the 3PP with mobile payment?

2. How does the 3PP entry affect the profits of the supply chain members?

3. What are the impacts of information sharing on the supply chain with the 3PP?

We have some interesting results as follows. First, we give the optimal decisions of the manufacturer, the retailer and the 3PP with mobile payment. In both the non-information sharing and information sharing cases, the $3 \mathrm{PP}$ should make a reasonable commission rate which can lure the retailer to introduce it as well as maintain its own profitability. As the proportion of the $3 \mathrm{PP}$ users increases, the $3 \mathrm{PP}$ should decrease the commission rate. As the discount factor of credit consumption increases, the 3PP first increases the commission rate and then decreases it. Given the fact that the 3PP entry decreases the consumer price sensitivity, the retailer increases the retail price to cover the $3 \mathrm{PP}$ commissions and gain a higher margin. Anticipating that the consumers and retailer will be less price sensitive, the manufacturer is motivated to increase the wholesale price as well. As the 3PP provides more benefit for the consumer market (when the proportion of 3PP users is higher, the grace period of credit consumption is lower, or the cash opportunity cost is lower), the manufacturer and the retailer will further increase the prices. Moreover, the 3PP entry allows price increase without sacrificing the demand, because of the decreased consumer price sensitivity.

Second, we reveal the effects of the 3PP entry on the expected profits of the manufacturer, the retailer and the supply chain in the cases of non-information sharing and information sharing. In both cases, the $3 \mathrm{PP}$ entry causes a win-lose situation for the manufacturer and the retailer. One may intuit that the retailer will always benefit from the $3 \mathrm{PP}$, as the retailer has the option of forgoing the 3PP if it is unprofitable. Indeed, given a specific wholesale price, the retailer may achieve a higher profit by introducing the 3PP. However, the retailer makes the decision after the manufacturer. The manufacturer can adjust the wholesale price with the anticipation of the retailer's reactions. If the manufacturer anticipates that the retailer will introduce the $3 \mathrm{PP}$, the manufacturer acknowledges that the consumers will be less price sensitive. This motivates the manufacturer to increase the wholesale price to a large extent. The manufacturer has a first mover advantage. Although the 
follower retailer intends to benefit from the 3PP, the benefit is deprived of by the leader manufacturer. Meanwhile, the retailer is burdened with the 3PP commissions. An unexpected consequence is that the retailer is harmed by the 3PP. As to the supply chain, the entry of 3PP increases the expected profit if the 3PP entry can significantly decrease consumer price sensitivity or its fixed investment cost is low.

Third, we examine the value of information sharing in supply chains with and without the 3PP. When the resolved market potential is lower than the expected market potential (i.e., a bad market), information sharing will drive the manufacturer and the retailer to decrease the prices, and drive the 3PP to increase the commission rate; When the resolved market potential is higher than the expected market potential (i.e., a good market), information sharing will drive the manufacturer and the retailer to increase the prices, and drive the 3PP to reduce the commission rate. In terms of expected profits, information sharing benefits the manufacturer and the 3PP but harms the retailer. It is intuitive that with information sharing, the manufacturer will make more informed decision and achieve a higher expected profit. For the 3PP, information sharing leads to higher wholesale and retail prices and more commissions in a good market, and allows the $3 \mathrm{PP}$ to increase the commission rate in a bad market where credit consumption is critical in stimulating demand. In both the good and bad markets, the 3PP can be better off from information sharing. Furthermore, while information sharing always decreases the expected profit for the supply chain without the 3PP, it may increase the expected profit for the supply chain with the 3PP. To improve the supply chain profitability, we suggest to provide incentives for retailer information sharing if the 3PP can significantly decrease consumer price sensitivity (i.e., the proportion of the 3PP users is higher, the grace period of credit consumption is lower, or the cash opportunity cost is lower).

The rest of this paper is organized as follows. Section 2 reviews the related literature. Section 3 introduces the model, and shows the equilibrium in the non-information sharing case and information sharing case. In Sect. 4, we analyze the equilibrium. Section 5 concludes the findings, discusses managerial insights, and proposes future research directions. All proofs are provided in the Appendix.

\section{Literature review}

Our research is related to three streams of research: supply chain intermediation, supply chain finance and information sharing. A large body of literature has recognized that the entry of an intermediation will significantly impact the supply chain members. Wu (2004) identifies transactional and informational advantages offered by supply chain intermediaries, including reducing information asymmetry between user groups and reducing costs of searching and matching. Belavina and Girotra (2012) find that intermediaries can improve supply chain performance through relationship advantages even without transactional and informational advantages. Yang and Babich (2014) find that buyers can benefit from the services of intermediaries which have better information on the supply risk. Adida et al. (2016) find that the entry of intermediaries will cause competition between them and the retailer. Kannan et al. (2017) propose a cost effective third-party reverse logistics which collect returned products from various companies. Govindan et al. (2018) show that outsourcing reverse logistics to the intermediaries is important, because they can help companies fulfil legislation requirements and increase customer satisfaction. Singh et al. (2018) show that third party logistics for cold chain management need to consider various 
criterion of the outsourcing firm. Zhen et al. (2020) find that a captical constricted manufacturer which sells products through a retailer and a third-party platform prefers the thirdparty platform credit financing to bank credit financing. Different from these studies, we focus on 3PPs which are the intermediary between retailers and consumers.

Second, our study is related to supply chain finance, as the 3PP provides credit consumption for consumers. Chen and Wang (2012) find that trade credit contract can create value for a two-level supply under budget constraints. Katehakis et al. (2016) study the optimal financing decision for the small-to-medium size enterprises in both single-period and multiple-period competition. Wuttke et al. (2016) show that it is often not optimal to introduce supply chain finance immediately but rather to wait until a specific fraction of suppliers are persuaded of the supply chain finance concept. Chen et al. (2018) conceptualize the cash flow dynamics in a supply chain consisting of a manufacturer, a buyer, and a third-party logistic firm which provides procurement and financial assistance to buyers. The study finds that the supply chain's profit can be higher under leadership by the third-party logistic firm than by the manufacturer. Yan et al. (2018) find that loss-averse retailers will order more under the supplier investment than under the supplier finance. Li et al. (2019) find that in a dual-channel supply chain consisting of a competitive supplier and a capital-constrained manufacturer, trade credit is an equilibrium strategy when the proportion of equity financing is large or small, and otherwise trade credit or hybrid financing is an equilibrium strategy. While the previous supply chain finance literature focuses on financing schemes between the manufacturer and the retailer, we consider the financing scheme for consumers-credit consumption. Our study reveals the impacts credit consumption on the pricing decisions of the retailer and the upstream manufacturer.

Third, our study is related to the information sharing literature. The use of the information is undoubtedly critical in modern supply chain management, which is investigated in vast literature. Ha and Tong (2008) find that a supply chain will lower its selling quantities when the supply chain does not have information sharing. Choi et al. (2008) show that information sharing is the most beneficial for suppliers when the yield variance is high and the demand variance is low. Shamir (2012) demonstrates that competing retailers can establish a cartel by using information leakage to signal their private information to one another. Shamir and Shin (2016) show that by making information publicly available to achieve information sharing can benefit all the firms in the market as well as consumers. Ha et al. (2016) show that if a manufacturer is efficient in cost reduction, information sharing will benefit the supply chain by reducing a manufacturer's wholesale price and unit production cost. Huang et al. (2018) demonstrate that retailers may prefer to voluntarily share their private demand information in anticipation of suppliers' potential for encroachment. Zhang et al. (2018) show that the information sharing can lead to environmentally friendlier and more efficient supply chain, and sharing the cost of information sharing can coordination the supply chain. Shen et al. (2019a, b) review the major application areas of information usage and report the historical development of major related topics. Following this stream of research, we consider that the manufacturer, the retailer and the 3PP may have asymmetric information, and examine the value of information sharing. 


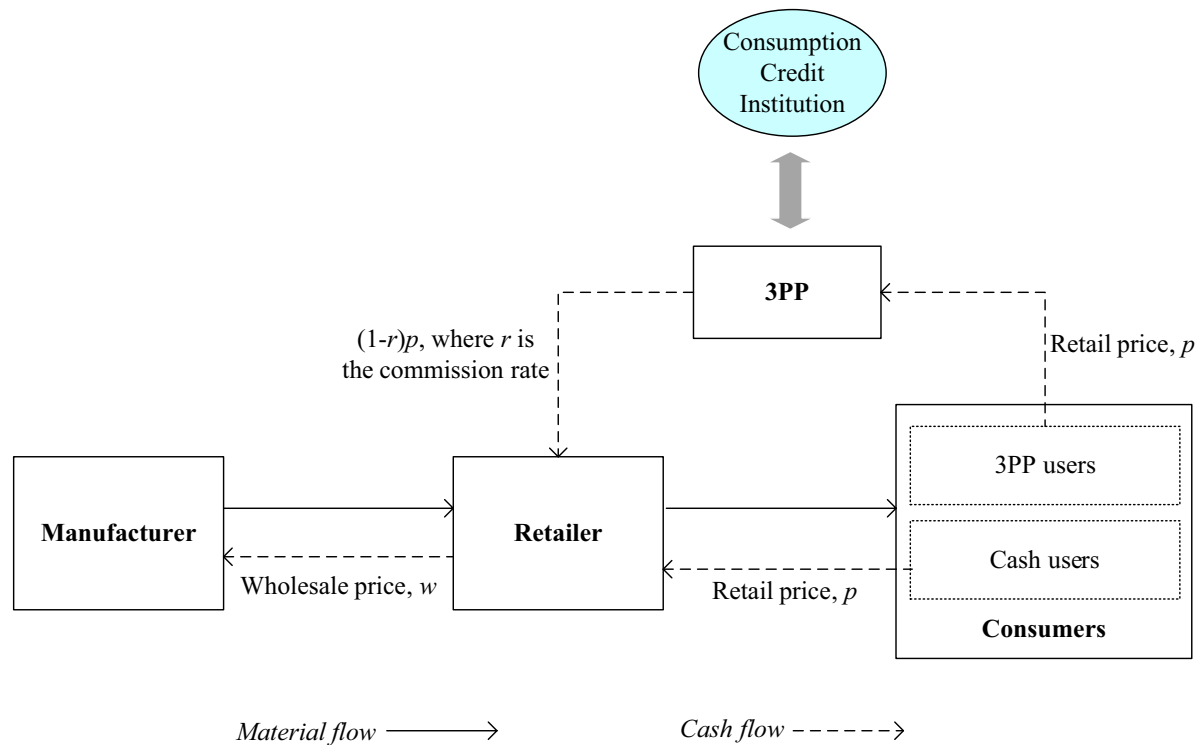

Fig. 1 Supply chain structure (the decisions of the consumption credit institution are exogenous)

\section{Model}

We consider a supply chain in which a manufacturer sells a product via an independent retailer. The manufacturer produces the product at a marginal cost which is normalized to zero, and sells it to the retailer at wholesale price $w$. The retailer resells it to consumers at retail price $p$. Without the 3PP, the consumers pay the retailer with cash. To provide the mobile payment service, the 3PP may enter the market with a fixed investment cost $F$, which includes developing information system and purchasing hardware (e.g., POS). The 3PP charges a commission rate $r$ for the payment. That is, if a consumer pays $p$ for a product via the 3PP, the 3PP charges $r p$ as the commission, and the retailer obtains the remaining $(1-r) p$. Figure 1 shows the supply chain structure.

Following Choi and Fredj (2013), Dong et al. (2019) and Shen et al. (2020), we establish a downward sloping linear demand function which is given by:

$$
\hat{q}=1-p+\varepsilon,
$$

where $\varepsilon$ represents the uncertainty level for the market potential. Following Huang et al. (2018), we assume that $\varepsilon$ is uniformly distributed in $[0,2 \xi]$. As such, $\xi$. denotes the expectation, and a higher $\xi$ leads to a higher expected market potential. In the non-information sharing case, the retailer and the 3PP can privately observe the resolved demand information $\hat{\varepsilon}$, but the manufacturer cannot. This indicates that that the retailer and the 3PP which are closer to consumers have more demand information than the manufacturer (Guo and Zhao 2009; Huang et al. 2018). In the information sharing case, the retailer shares the information with the manufacturer, and thus all of the supply chain members know the resolved market potential $\hat{\varepsilon}$.

Introducing the 3PP will affect the demand function in Eq. (1), because the 3PP facilitates credit consumption and decreases consumer price sensitivity. If the retailer introduces 
the 3PP, the consumers have two payment options: paying through the $3 \mathrm{PP}$ or in cash. We consider $\lambda$ proportion of consumers prefer paying through $3 \mathrm{PP}$, and the remaining $1-\lambda$ proportion prefer paying in cash, where $0 \leq \lambda \leq 1$. The 3PP users benefit from the opportunity cost of cash, because the $3 \mathrm{PP}$ provides credit consumption and allows delay payment. The actual price for the 3PP users is $p /(1+I l)$, where $I$ is the unit cash opportunity cost per time unit (e.g., interest rate) and $l$ is the grace period (Chen et al. 2018). For ease of exposition, let $\delta=1 /(1+I l)$ denote the discount factor of credit consumption and we have $0 \leq \delta \leq 1$. A lower $\delta$ (which occurs when $I$ and $l$ are higher) implies that consumers can gain more benefit from credit consumption. We consider that without the entry of $3 \mathrm{PP}$, the retailer does not allow credit consumption. This is true for small retailers because commercial banks are not interested in serving them or because they are not qualified.

When the 3PP is introduced, the demand from the 3PP users is:

$$
q_{p}=\lambda(1-\delta p+\varepsilon)
$$

The demand from the cash users is:

$$
q_{n}=(1-\lambda)(1-p+\varepsilon) .
$$

The total demand for the product is:

$$
q=q_{p}+q_{n}=\lambda(1-\delta p+\varepsilon)+(1-\lambda)(1-p+\varepsilon)=1-X p+\varepsilon,
$$

where $X=1-\lambda+\lambda \delta$ represents the price sensitivity with the 3PP entry. We have $0<X<1$, which indicates that the 3PP entry can decrease the price sensitivity.

The profits of the retailer, the $3 \mathrm{PP}$ and the manufacturer are:

$$
\begin{gathered}
\pi_{r}=(p-w) q_{N}+[(1-r) p-w] q_{P}, \\
\pi_{p}=r p q_{P}-F, \\
\pi_{m}=w q .
\end{gathered}
$$

The supply chain's profit is:

$$
\pi_{c}=\pi_{r}+\pi_{p}+\pi_{m}=p q-F .
$$

The game sequence is as follows. In Stage 1, the manufacturer sets the wholesale price, $w$. In Stage 2, the retailer sets the retail price, $p$. In Stage 3, the 3PP sets the commission rate, $r$. In Stage 4 , the retailer decides on whether to introduce the 3PP or not. All of the supply chain members are risk neutral and maximize their own expected profit. Our following analysis focuses on $X>\frac{2}{3}$, which indicates that the discount factor of credit consumption is not extremely low. Because the supply chain has zero profit in the non-information sharing case when $\hat{\varepsilon} \leq \frac{(2-X) \xi-3 X+2}{2 X}$, we assume $\xi<\frac{3 X-2}{2-X}$ which is sufficient condition to ensure supply chain profitability. The notation in the paper is summarized in Table 2. 
Table 2 Summary of notation

\begin{tabular}{ll}
\hline Notation & Meaning \\
\hline$p$ & The retail price \\
$w$ & The wholesale price \\
$\varepsilon$ & The uncertainty level for the market potential \\
$\hat{\varepsilon}$ & The resolved uncertainty part of the market potential \\
$\xi$ & The expected uncertainty part of the market potential \\
$q$ & The total demand for the product \\
$\lambda$ & The proportion of the 3PP users \\
$I$ & The unit cash opportunity cost \\
$l$ & The grace period of credit consumption \\
$\delta$ & The discount factor of credit consumption, and $\delta=1 /(1+I l)$ \\
$X$ & The consumer price sensitivity with the 3PP entry, and $X=1-\lambda+\lambda \delta$ \\
$r$ & The commission rate of the 3PP \\
$F$ & The fixed investment cost of the 3PP \\
$q_{n}$ & The demand from the cash users \\
$q_{p}$ & The demand from the 3PP users \\
$\pi_{m}$ & The manufacturer's profit \\
$\pi_{r}$ & The retailer's profit \\
$\pi_{p}$ & The 3PP's profit \\
$\pi_{c}$ & The supply chain's profit \\
\hline
\end{tabular}

\subsection{Non-information sharing case}

In Sect. 3.1, we consider the non-information sharing case (denoted by subscript ' $N$ ') where the retailer and the 3PP does not share the information $\hat{\varepsilon}$ with the manufacturer. We study two different supply chain models, with and without the 3PP. Notice that the model without the $3 \mathrm{PP}$ is a special case of the model with the $3 \mathrm{PP}$ if we set $\lambda=0$ or $X=1 .^{3}$ The sub-game perfect equilibrium is given in Table 3.

We have the following results from Table 3. First, we find that as $\lambda$ increases or $\delta$ decreases, the optimal retail and wholesale prices increase. A higher $\lambda$ or a lower $\delta$ implies that the 3PP entry will decrease consumer price sensitivity more significantly. This incentivizes the retailer to increase the retail price to gain a higher margin, which further motivates the manufacturer to increase the wholesale price too. Second, we find that the optimal commission rate decreases in $\lambda$. The reason is as follows. As the 3PP users increase, the retailer suffers more losses from the commissions if introducing the 3PP. The 3PP has to reduce the commission rate to attract the retailer. In addition, the optimal commission rate increases in $\delta$ when $\delta$ is low, and decreases in $\delta$ when $\delta$ is high. Third, a higher $\lambda$ or a lower $\delta$ leads to higher expected profits for the 3PP and the supply chain and a lower expected profit for the retailer. The retailer which is cooperating with the $3 \mathrm{PP}$ is worse off if the 3PP becomes more advantaged.

${ }^{3}$ We thank the anonymous review for the insightful comment. 


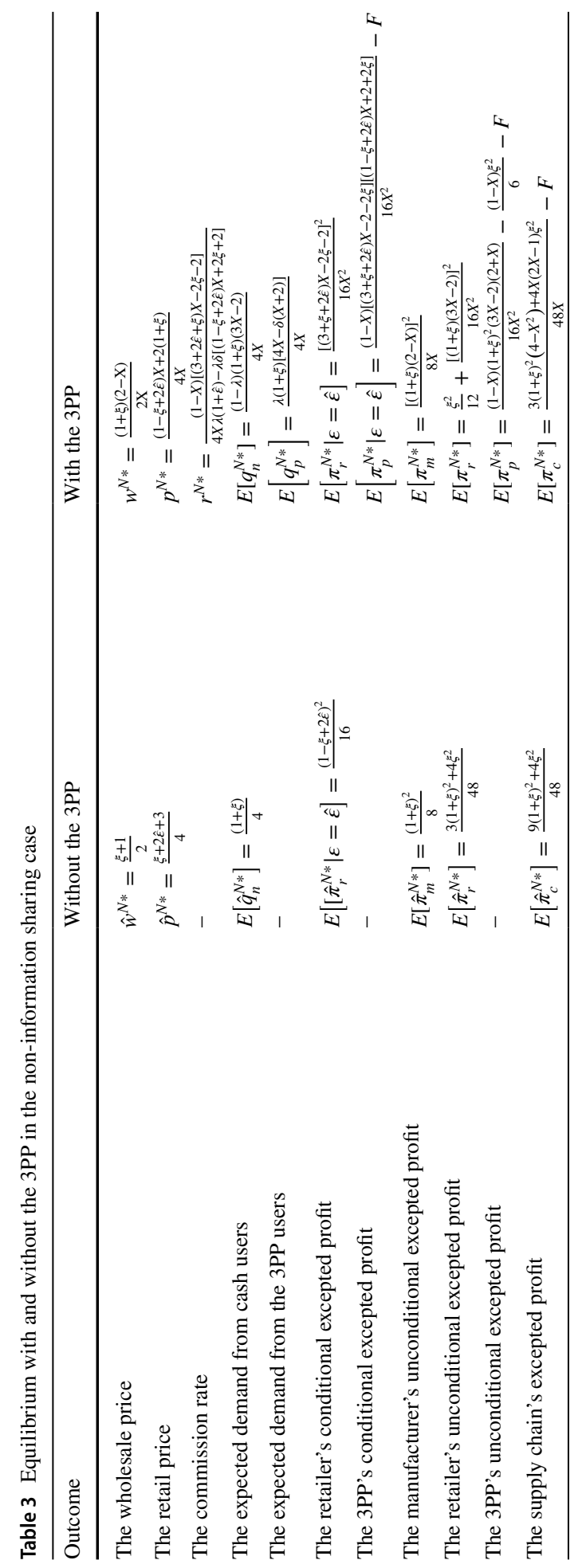


Table 4 Equilibrium with and without the $3 \mathrm{PP}$ in the information sharing case

\begin{tabular}{|c|c|c|}
\hline Outcome & Without the 3PP & With the 3PP \\
\hline The wholesale price & $\hat{w}^{I *}=\frac{1+\hat{\varepsilon}}{2}$ & $w^{I *}=\frac{(1+\hat{\varepsilon})(2-X)}{2 X}$ \\
\hline The retail price & $\hat{p}^{I *}=\frac{3+3 \hat{\varepsilon}}{4}$ & $p^{I *}=\frac{(1+\hat{\varepsilon})(2+X)}{4 X}$ \\
\hline The commission rate & - & $r^{I *}=\frac{(1-X)(3 X-2)}{4 X \lambda-\lambda \delta(X+2)}$ \\
\hline $\begin{array}{l}\text { The excepted demand from } \\
\text { cash users }\end{array}$ & $E\left[\hat{q}_{n}^{I *}\right]=\frac{1+\xi}{4}$ & $E\left[q_{n}^{I *}\right]=\frac{(1-\lambda)(1+\xi)(3 X-2)}{4 X}$ \\
\hline $\begin{array}{l}\text { The excepted demand from the } \\
\text { 3PP users }\end{array}$ & - & $E\left[q_{p}^{I *}\right]=\frac{\lambda(1+\xi)[4 X-\delta(X+2)]}{4 X}$ \\
\hline $\begin{array}{l}\text { The manufacturer's conditional } \\
\text { excepted profit }\end{array}$ & $E\left[\hat{\pi}_{m}^{I *} \mid \varepsilon=\hat{\varepsilon}\right]=\frac{(1+\hat{\varepsilon})^{2}}{8}$ & $E\left[\pi_{m}^{I *} \mid \varepsilon=\hat{\varepsilon}\right]=\frac{((1+\hat{\varepsilon})(2-X))^{2}}{8 X}$ \\
\hline $\begin{array}{l}\text { The retailer's conditional } \\
\text { excepted profit }\end{array}$ & $E\left[\pi_{r}^{I *} \mid \varepsilon=\hat{\varepsilon}\right]=\frac{(1+\hat{\varepsilon})^{2}}{16}$ & $E\left[\pi_{r}^{I *} \mid \varepsilon=\hat{\varepsilon}\right]=\frac{((1+\hat{\varepsilon})(3 X-2))^{2}}{16 X^{2}}$ \\
\hline $\begin{array}{l}\text { The 3PP's conditional excepted } \\
\text { profit }\end{array}$ & - & $E\left[\pi_{p}^{I *} \mid \varepsilon=\hat{\varepsilon}\right]=\frac{(1-X)(1+\hat{\varepsilon})^{2}(3 X-2)(X+2)}{16 X^{2}}-F$ \\
\hline $\begin{array}{l}\text { The manufacturer's uncondi- } \\
\text { tional excepted profit }\end{array}$ & $E\left[\hat{\pi}_{m}^{I *}\right]=\frac{4 \xi^{2}+6 \xi+3}{24}$ & $E\left[\pi_{m}^{I *}\right]=\frac{(2-X)^{2}\left(4 \xi^{2}+6 \xi+3\right)}{24 X}$ \\
\hline $\begin{array}{l}\text { The retailer's unconditional } \\
\text { excepted profit }\end{array}$ & $E\left[\hat{\pi}_{r}^{I *}\right]=\frac{\xi^{2}+3(1+\xi)^{2}}{48}$ & $E\left[\pi_{r}^{I *}\right]=\frac{(3 X-2)^{2}\left(4 \xi^{2}+6 \xi+3\right)}{48 \mathrm{X}^{2}}$ \\
\hline $\begin{array}{l}\text { The 3PP's unconditional } \\
\text { excepted profit }\end{array}$ & - & $E\left[\pi_{p}^{I *}\right]=\frac{\left(\xi^{2}+6 \xi+3\right)(1-X)(3 X-2)(X+2)}{48 X^{2}}-F$ \\
\hline $\begin{array}{l}\text { The supply chain's uncondi- } \\
\text { tional excepted profit }\end{array}$ & $E\left[\hat{\pi}_{c}^{I *}\right]=\frac{\xi^{2}+3(1+\xi)^{2}}{16}$ & $E\left[\pi_{c}^{l *}\right]=\frac{3(1+\xi)^{2}\left(4-X^{2}\right)+(2+X)\left(2 X^{2}-3 X+2\right) \xi^{2}}{48 X}-\frac{(1-X)\left(3 X^{2}+4 X-4\right) \xi^{2}}{24 X^{2}}-F$ \\
\hline
\end{tabular}

\subsection{Information sharing case}

We next consider the information sharing case (denoted by subscript ' $T$ ') where the retailer and the $3 \mathrm{PP}$ share the information $\hat{\varepsilon}$ with the manufacturer. The equilibrium is given in Table 4. We find that the impacts of $\lambda$ and $\delta$ on the equilibrium are the same in the noninformation sharing and the information sharing cases.

\section{Analysis}

Based on equilibrium of four models - without the 3PP and non-information sharing, with the 3PP and non-information sharing, without the 3PP and information sharing, and with the 3PP and information sharing, we can reveal the effects of the 3PP entry and the effects of information sharing.

\subsection{Effects of the 3PP entry}

In Sect. 4.1, we compare the equilibrium with and without the 3PP to examine the effects of the $3 \mathrm{PP}$ entry in each information case.

Proposition 1 By comparing the equilibrium prices and expected quantities with and without the $3 P P$, we have: 
1. $w^{i *}>\hat{w}^{i *}$ and $p^{i *}>\hat{p}^{i *}$,

2. $E\left[q_{n}^{i *}\right]<E\left[\hat{q}_{n}^{*}\right]$ and $E\left[q^{i *}\right]>E\left[\hat{q}^{i *}\right]$,

where $i=N$ or $I$.

Proposition 1 (1) shows that the entry of 3PP will increase the wholesale price and the retail price in both the non-information sharing case and the information sharing case. There are two reasons for the retailer to increase the price in response to the 3PP entry. First, the retailer needs to pay a certain amount of commission to the $3 \mathrm{PP}$, and the retailer has to increase the price to cover the additional cost. Second, the 3PP entry facilitates credit consumption and decreases price sensitivity, which incentivizes the retailer to increase the price to gain a higher margin. The manufacturer, which anticipates the price enhancement of the downstream retailer, is motivated to increase the wholesale price as well.

Proposition 1 (2) shows that 3PP entry increases the total demand in both the noninformation sharing case and the information sharing case. This implies that mobile payment and the 3PP entry allows the retailer to increase the price without compromising the demand, because of the decreased price sensitivity. Not surprisingly, the entry of 3PP decreases the amount of consumers who pay in cash. In fact, this may benefit the retailer because paying in cash generally incurs significant higher operational cost for the retailer. Some interesting news reported that, thieves have made a fresh start and behaved well because the convenience stores in China have little cash. ${ }^{4}$

Proposition 2 By comparing the equilibrium unconditional expected profits with and without the 3PP, we have the following results.

1. In the non-information sharing case, we have $E\left[\pi_{m}^{N *}\right]>E\left[\hat{\pi}_{m}^{N *}\right]$ and $E\left[\pi_{r}^{N *}\right]<E\left[\hat{\pi}_{r}^{N *}\right]$; and we have $E\left[\pi_{c}^{N *}\right]>E\left[\hat{\pi}_{c}^{N *}\right]$ if and only if $F<\frac{3(1+\xi)^{2}\left(4-X^{2}\right)+4 X\left[(2 X-1) \xi^{2}\right]}{48 X}$.

2. In the information sharing case, we have $E\left[\pi_{m}^{I *}\right]>E\left[\hat{\pi}_{m}^{I *}\right]$ and $E\left[\pi_{r}^{I *}\right]<E\left[\hat{\pi}_{r}^{I *}\right]$; and we have $E\left[\pi_{c}^{I *}\right]>E\left[\hat{\pi}_{c}^{I *}\right]$ if and onlyif $F<\frac{3(1+\xi)^{2}\left(4-X^{2}\right)+\left[(3 X-2)^{2}+2 X(X-2)^{2}\right] \xi^{2}}{48 X}-\frac{(1-X)\left(3 X^{2}+4 X-4\right) \xi^{2}}{24 X^{2}}$.

Proposition 2 shows that in both the non-information sharing and information sharing cases, the entry of 3PP causes a win-lose situation for the manufacturer and the retailer, and may increase or decrease the supply chain's profit. Given the wholesale price, the retailer will introduce the $3 \mathrm{PP}$ if and only if it is profitable, and thus the retailer can be better off from the 3PP entry. But this is not true if the upstream manufacturer can adjust the wholesale price accordingly. The manufacturer which anticipates the 3PP entry and decreased price sensitivity will increase the wholesale price to a large extent. The first mover manufacturer seizes all of the benefit of the 3PP entry from the retailer, leaving the retailer burdened with the commissions for the 3PP. As a consequence, the 3PP entry benefits the manufacturer but harms the retailer. For the supply chain, the entry of $3 \mathrm{PP}$ increases the expected profit if the fixed investment cost of the 3PP is low, otherwise decreases the expected profit.

${ }^{4}$ https://www.sohu.com/a/197649388_114760. 


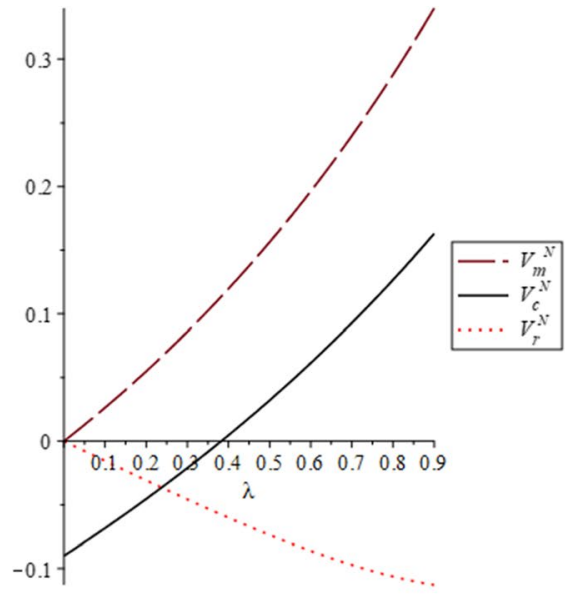

(a) The non-information sharing case

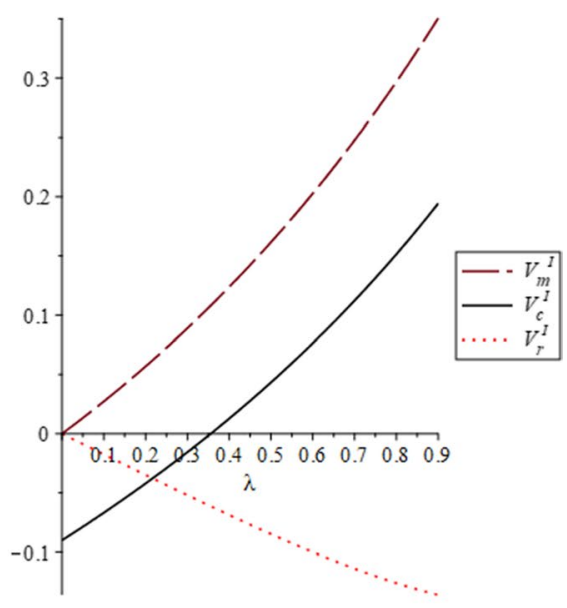

(b) The information sharing case

Fig. 2 Value of the 3PP entry (depicted with $\delta=0.7, \xi=0.5$, and $F=0.09$ )

We examine the value of the 3PP. Let $V_{m}^{i}=E\left[\pi_{m}^{i *}\right]-E\left[\hat{\pi}_{m}^{i *}\right]$ denote the value of the 3PP for the manufacturer, $V_{r}^{i}=E\left[\pi_{m}^{i *}\right]-E\left[\hat{\pi}_{m}^{i *}\right]$ denote the value of the 3PP for the retailer, and $V_{c}=E\left[\pi_{c}^{i *}\right]-E\left[\hat{\pi}_{c}^{i *}\right]$ denote the value of the 3PP for the supply chain in case $i(=N$ or $I)$. The numerical results in the non-information sharing and information sharing cases are shown in Fig. 2, respectively. We observe that when $\lambda$ or $\theta$ are higher, i.e., the 3PP provides more benefit for the consumer market, the 3PP creates more value for the manufacturer and the supply chain but harms the retailer more. Counterintuitively, the more beneficial the $3 \mathrm{PP}$ is, the more loss the retailer suffers.

\subsection{Effects of information sharing}

In Sect. 4.2, we compare the non-information sharing case and the information sharing case to reveal the value of information sharing.

Proposition 3 By comparing the equilibrium decisions in the non-information sharing and information sharing cases, we have $w^{I *}<w^{N *}, p^{I *}<p^{N *}$ and $r^{I *}>r^{N *}$ when $\hat{\varepsilon} \leq \xi$, and $w^{I *}>w^{N *}, p^{I *}>p^{N *}$ and $r^{I *}<r^{N *}$ when $\hat{\varepsilon}>\xi$.

Notice that $\hat{\varepsilon} \leq \xi$ implies a bad market and $\hat{\varepsilon}>\xi$ implies a good market. If the retailer shares the information of a bad market, it leads to lower wholesale and retail prices and alleviate the double marginalization effect; and if the retailer shares the information of a good market, it leads to higher wholesale price and retail prices and increases the double marginalization effect. This is because the manufacturer sets the wholesale price according to the mean of the market potential in the non-information sharing case, and information sharing drives the manufacturer's decision from that. Given that the optimal commission rate decreases in the wholesale price, information sharing increases the 3PP's commission rate in a bad market and decreases the 3PP's commission rate in a good market. 
Fig. 3 Impacts of information sharing on the expected profit for the supply chain with the $3 \mathrm{PP}$

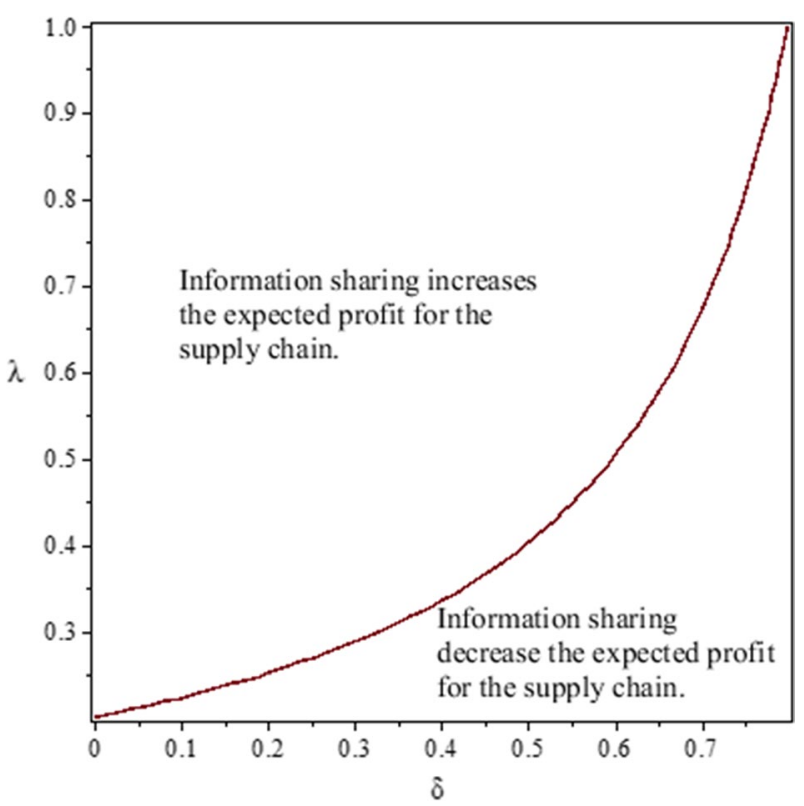

Proposition 4 By comparing the equilibrium excepted profits in the non-information sharing and information sharing cases, we have the following results.

1. In the supply chain without the $3 P P$, we have $E\left[\hat{\pi}_{m}^{N *}\right]<E\left[\hat{\pi}_{m}^{I *}\right], E\left[\hat{\pi}_{r}^{N *}\right]>E\left[\hat{\pi}_{r}^{I *}\right]$, and $E\left[\hat{\pi}_{c}^{N *}\right]>E\left[\hat{\pi}_{c}^{I *}\right]$.

2. In the supply chain with the $3 P P$, we have $E\left[\pi_{m}^{N *}\right]<E\left[\pi_{m}^{I *}\right], E\left[\pi_{r}^{N *}\right]>E\left[\pi_{r}^{I *}\right]$ , $E\left[\pi_{p}^{N *}\right]>E\left[\pi_{p}^{I *}\right]$; and $E\left[\pi_{c}^{N *}\right]>E\left[\pi_{c}^{I *}\right]$ if and only if $\mathrm{X}>\bar{X}$, where $\bar{X} \in\left(\frac{2}{3}, 1\right)$ is determined by $2 \bar{X}^{4}-\bar{X}^{3}+2 \bar{X}^{2}-12 \bar{X}+8=0$.

Proposition 4 reveals that information sharing benefits the manufacturer and the 3PP, but harms the retailer. With or without the 3PP entry, the manufacturer always benefits from information sharing, because it provides more accurate information for the decision making. Information sharing also increases the expected profit for the $3 \mathrm{PP}$, because it leads to a higher retail price and more commissions for the $3 \mathrm{PP}$ in a good market and allows the 3PP to increase the commission rate in a bad market. However, the retailer prefers to maintain the information privilege rather than sharing the information with the manufacturer. That is, the retailer will not volunteer to share the information.

Next, we discuss the effects of information sharing on the supply chain. For the supply chain without the $3 \mathrm{PP}$, information sharing always decreases the expected profit; however, for the supply chain with the 3PP, information sharing increases the expected profit when $X$ is low and decreases the expected profit when $X$ is high. Recall that $X=1-\lambda+\lambda \delta$ represents the price sensitivity with the 3PP entry. A lower $X$ implies that the 3PP entry is considerably beneficial for the consumer market and thus 


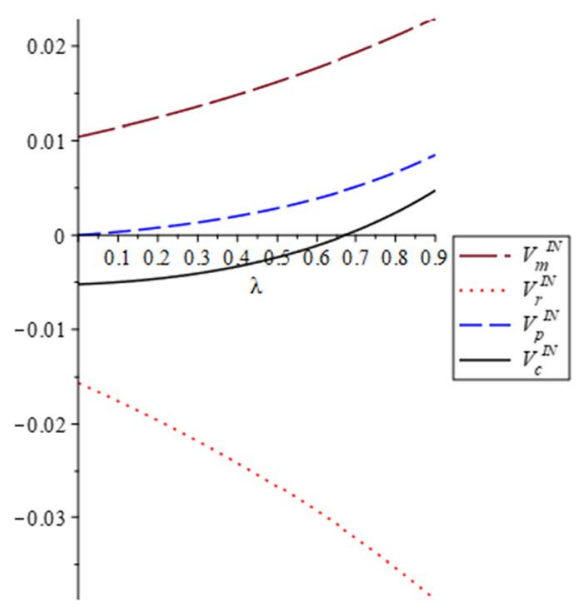

(a) Depicted with $\delta=0.7$ and $\xi=0.5$.

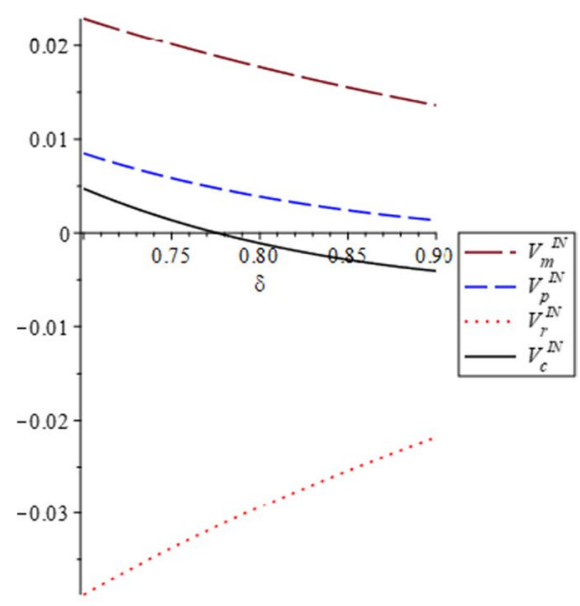

(b) Depicted with $\lambda=0.9$ and $\xi=0.5$.

Fig. 4 Value of information sharing in the supply chain with the 3PP

significantly reduces the price sensitivity. Specifically, a lower $X$ occurs when $\lambda$ is high and $\delta$ is low, as shown in Fig. 3.

Furthermore, we examine the value of information sharing. Let $V_{m}^{I N}=E\left[\pi_{m}^{I *}\right]-E\left[\pi_{m}^{N *}\right.$ denote the value of information sharing for the manufacturer, $V_{r}^{I N}=E\left[\pi_{r}^{I *}\right]-E\left[\pi_{r}^{N *}\right]$ denote value of information sharing for the retailer, $V_{p}^{I N}=E\left[\pi_{p}^{I *}\right]-E\left[\pi_{p}^{N *}\right]^{r}$ denote the value of information sharing for the $3 \mathrm{PP}$, and $V_{c}^{I N}=E\left[\pi_{c}^{I *}\right]-E\left[\pi_{c}^{N *}\right]$ denote the value of information sharing for the supply chain. To better understand the results, we conduct numerical experiments in Fig. 4 Consistent with our analytical results, we have $V_{m}^{I N}>0, V_{r}^{I N}<0, V_{p}^{I N}>0$ and $V_{c}^{I N}>$ or $\leq 0$. Moreover, the numerical experiments show that, as $\lambda$ increases or $\delta$ decreases, information sharing creates more value for the manufacturer, the $3 \mathrm{PP}$ and the supply chain, but harms the retailer more.

\section{Conclusion}

Motivated by the prevalence of mobile payment, this study builds game-theoretic models to conceptualize the impacts of third-party payment platforms (3PPs) on supply chains: change of cash flow, decrease of consumer price sensitivity, and feasibility of information sharing. We study four supply chain models: without the 3PP and non-information sharing, with the 3PP and non-information sharing, without the 3PP and information sharing, and with the 3PP and information sharing. By analyzing the equilibrium, we answer the research questions and provide suggestions for enterprises.

In both the information sharing and non-information sharing cases, we have the following findings on the implications of the 3PP entry. The 3PP entry which facilitates credit consumption can decrease consumer price sensitivity. This effect is more significant when the proportion of 3PP users is higher, the grace period of credit consumption is lower, or the cash opportunity cost is lower. Because of the decreased price sensitivity, the 3PP entry leads to higher wholesale and retail prices, as well as higher demand. 
Although the retailer can gain a higher margin, it has to undertake the 3PP commissions. Meanwhile, the first mover manufacturer increases the wholesale price to a large extent to seize all of the benefit provided by the 3PP. As a result, the 3PP entry causes a win-lose situation for the manufacturer and the retailer. For the supply chain, the 3PP entry is desirable if it can significantly decrease consumer price sensitivity or its fixed investment cost is low.

By comparing the information sharing and non-information sharing cases, we reveal the effects of information sharing. When the resolved market potential is lower than the expected market potential (i.e., a bad market), information sharing will drive the manufacturer and the retailer to decrease the respective price, which mitigates the double marginalization effect; When the resolved market potential is higher than the expected market potential (i.e., a good market), information sharing will drive the manufacturer and the retailer to increase the respective price, which increase the double marginalization effect. Information sharing benefits the manufacturer and the 3PP but harms the retailer. Moreover, while information sharing always decreases the expected profit for the supply chain without the 3PP, it may increase the expected profit for the supply chain with the 3PP.

A number of questions remain unaddressed in this study, and may be worth future investigation. First, mobile payment can effectively reduce the operational cost of retailers. The mobile pay not only reduces the computing time of service personnel, but also reduces the cost of retailer and saves the time of consumers. To focus on our research questions, our model does not incorporate the operational cost; and therefore, we are unable to conceptualize this characteristic of mobile pay. Second, future studies can extend the model to study different game sequence. For example, the 3PP is the game leader, and the manufacturer and the retailer can responsively adjust the prices. Third, we consider a supply chain consists of a single retailer, a single 3PP, and a single manufacturer, and do not consider the competition in the supply chain. Forth, we assume the uncertainty level of the market potential follows a uniform distribution. Future research can extend to consider a normal distribution, see, for example, Chan et al. (2017), Choi et al. (2018), Shen et al. (2019a, b), and Shi and Shen (2019). Moreover, future studies can consider risk attitude of supply chain members, see, for example, Chiu et al. (2018).

Acknowledgements This research is supported by National Natural Science Foundation of China (Nos. 71772115, 71372187, 71901137).

\section{Appendix}

\section{Derivation of the equilibrium in the non-information sharing case}

We find the sub-game perfect equilibrium by backward induction.

In Stage 4, given $w, p$ and $r$, the retailer decides on whether to introduce the 3PP or not. When the 3PP does not exist, $E\left[\hat{\pi}_{r} \mid \varepsilon=\hat{\varepsilon}\right]=(p-w)(1-p+\hat{\varepsilon})$; when the 3PP exists, $E\left[\pi_{r} \mid \varepsilon=\hat{\varepsilon}\right]=(p-w)(1-X p+\hat{\varepsilon})-r p q_{p}$. Hence, the retailer will introduce the 3PP if and only if $E\left[\pi_{r} \mid \varepsilon=\hat{\varepsilon}\right] \geq E\left[\hat{\pi}_{r} \mid \varepsilon=\hat{\varepsilon}\right]$ i.e., $r \leq \frac{(1-X)(p-w)}{\lambda(1+\hat{\varepsilon})-(\lambda+X-1) p}$; and the retailer will not introduce the 3PP if and only if $E\left[\pi_{r} \mid \varepsilon=\hat{\varepsilon}\right]<E\left[\hat{\pi}_{r} \mid \varepsilon=\hat{\varepsilon}\right]$, i.e., $r>\frac{(1-X)(p-w)}{\lambda(1+\hat{\varepsilon})-(\lambda+X-1) p}$. 
In Stage 3, given $w$ and $p$, the 3PP decides on the commission rate $r$ to maximize its profit given by:

$$
E\left[\pi_{p} \mid \varepsilon=\hat{\varepsilon}\right]= \begin{cases}r p(\lambda(1+\hat{\varepsilon})-(X+\lambda-1) p)-F & \text { if } r \leq \frac{(1-X)(p-w)}{\lambda(1+\hat{\varepsilon})-(\lambda+X-1) p} \\ 0 & \text { if } r>\frac{(1-X)(p-w)}{\lambda(1+\hat{\varepsilon})-(\lambda+X-1) p}\end{cases}
$$

Setting $r>\frac{(1-X)(p-w)}{\lambda(1+\hat{\varepsilon})-(\lambda+X-1) p}$ leads to zero profit and is a dominated strategy for the 3PP. Thus, the 3PP's optimal decision should satisfy $r \leq \frac{(1-X)(p-w)}{\lambda(1+\hat{\varepsilon})-(\lambda+X-1) p}$, when we have $\frac{\partial E\left[\pi_{p} \mid \varepsilon=\hat{\varepsilon}\right]}{\partial r}=p q_{p} \geq 0$, i.e., the 3PP's profit is non-decreasing in $r$. The optimal decision of the $3 \mathrm{PP}$ is

$$
r^{N *}=\frac{(1-X)(p-w)}{\lambda(1+\hat{\varepsilon})-(\lambda+X-1) p} .
$$

In Stage 2, given $w$, the retailer determines $p$ to maximize its expected profit. Substituting Eq. (10) into $E\left[\pi_{r} \mid \varepsilon=\hat{\varepsilon}\right]$, we have:

$$
E\left[\pi_{r} \mid \varepsilon=\hat{\varepsilon}\right]=(p-w)(1-X p+\hat{\varepsilon})-\frac{(1-X)(p-w)}{\lambda(1+\hat{\varepsilon})-(\lambda+X-1) p}(\lambda(1+\hat{\varepsilon})-(\lambda+X-1) p) p .
$$

Since $\pi_{r}$ is concave in $p\left(\frac{\partial^{2} E\left[\pi_{r} \mid \varepsilon=\hat{\varepsilon}\right]}{\partial p^{2}}=-2<0\right)$, we can obtain the best response $p$ by solving the first order condition, $\frac{\partial E\left[\pi_{r} p^{2}=\hat{\varepsilon}\right]}{\partial p}=0$, i.e.,

$$
p=\frac{w+1+\hat{\varepsilon}}{2}
$$

In Stage 1, anticipating the best responses of the retailer and the platform, the manufacturer decides on the optimal $w$ to maximize its expected profit given by:

$$
E\left[\pi_{m}\right]=w\left(1-\frac{w+1+\xi}{2} X+\xi\right),
$$

subject to $w<p$. Because $E\left[\pi_{m}\right]$ is a concave function in $w$, we can derive the optimal decision by solving $\frac{\partial E\left[\pi_{m}\right]}{\partial w}=0$, i.e.,

$$
w^{N *}=\frac{-(1+\xi) X+2 \xi+2}{2 \mathrm{X}},
$$

which self satisfies $w<p$.

By substituting Eq. (14) into Eq. (12), we have the equilibrium retail price:

$$
p^{N *}=\frac{(1-\xi+2 \hat{\varepsilon}) X+2 \xi+2}{4 X} .
$$

By substituting Eqs. (14)-(15) into Eq. (10), we have:

$$
r^{N *}=\frac{(1-X)((3+2 \hat{\varepsilon}+\xi) X-2 \xi-2)}{4 X \lambda(1+\hat{\varepsilon})-(\lambda+X-1)((1-\xi+2 \hat{\varepsilon}) X+2 \xi+2)} .
$$



have:

By substituting Eqs. (14), (15), and (16) into $E\left[\pi_{m}\right], E\left[\pi_{r} \mid \varepsilon=\hat{\varepsilon}\right]$, and $E\left[\pi_{p} \mid \varepsilon=\hat{\varepsilon}\right]$, we

$$
\begin{gathered}
E\left[\pi_{m}^{N *}\right]=\frac{((1+\xi)(2-X))^{2}}{8 X}, \\
E\left[\pi_{r}^{N *} \mid \varepsilon=\hat{\varepsilon}\right]=\frac{((3+\xi+2 \hat{\varepsilon}) X-2 \xi-2)^{2}}{16 X^{2}}, \\
E\left[\pi_{p}^{N *} \mid \varepsilon=\hat{\varepsilon}\right]=\frac{(1-X)((3+\xi+2) X-2-2 \xi)((1-\xi+2 \hat{\varepsilon}) X+2+2 \xi)}{16 X^{2}}-F .
\end{gathered}
$$

The unconditional expected profits of the retailer and the 3PP are:

$$
\begin{gathered}
E\left[\pi_{r}^{N *}\right]=E\left[E\left[\pi_{r}^{N *} \mid \varepsilon=\hat{\varepsilon}\right]\right]=\frac{\xi^{2}}{12}+\frac{((1+\xi)(3 X-2))^{2}}{16 X^{2}}, \\
E\left[\pi_{p}^{N *}\right]=E\left[E\left[\pi_{p}^{N *} \mid \varepsilon=\hat{\varepsilon}\right]\right]=\frac{(1-X)(1+\xi)^{2}(3 X-2)(2+X)}{16 X^{2}}-\frac{(1-X) \xi^{2}}{6}-F .
\end{gathered}
$$

Thus, the unconditional expected profit of the supply chain is:

$$
E\left[\pi_{c}^{N *}\right]=\frac{3(1+\xi)^{2}\left(4-X^{2}\right)-4 X\left(12 F-(2 X-1) \xi^{2}\right)}{48 X} .
$$

The equilibrium is summarized in Table 3 .

\section{Derivation of the equilibrium in the information sharing case}

We derive the equilibrium by backward induction. In Stages 2-4, the decisions of the retailer and the 3PP are the same in the asymmetric and symmetric cases.

In Stage 1, anticipating the best responses of the retailer and the 3PP, the manufacturer decides on the optimal $w$ to maximize its expected profit given by:

$$
E\left[\pi_{m} \mid \varepsilon=\hat{\varepsilon}\right]=w\left[1-\frac{(w+1+\hat{\varepsilon}) X}{2}+\hat{\varepsilon}\right],
$$

subject to $w<p$. Because $E\left[\pi_{m} \mid \varepsilon=\hat{\varepsilon}\right]$ is a concave function of $w$, we can obtain the interior solution by solving $\frac{\partial E\left[\pi_{m} \mid \varepsilon=\varepsilon\right]}{\partial w}=0$, i.e.,

$$
w^{I *}=\frac{(1+\hat{\varepsilon})(2-X)}{2 X},
$$

which self satisfies $w<p$.

By substituting Eq. (24) into Eq. (12), we have the equilibrium retail price:

$$
p^{I *}=\frac{(1+\hat{\varepsilon})(2+X)}{4 X} .
$$

By substituting Eqs. (24)-(25) into Eq. (10), we have: 


$$
r^{I *}=\frac{(1-X)(3 X-2)}{4 X \lambda-(\lambda+X-1)(X+2)} .
$$

By substituting Eqs. (24), (25), and (26) into $E\left[\pi_{p} \mid \varepsilon=\hat{\varepsilon}\right], E\left[\pi_{r} \mid \varepsilon=\hat{\varepsilon}\right], E\left[\pi_{m} \mid \varepsilon=\hat{\varepsilon}\right]$ we have:

$$
\begin{gathered}
E\left[\pi_{p}^{I *} \mid \varepsilon=\hat{\varepsilon}\right]=\frac{(1-X)(1+\hat{\varepsilon})^{2}(3 X-2)(X+2)}{16 X^{2}}-F, \\
E\left[\pi_{r}^{I *} \mid \varepsilon=\hat{\varepsilon}\right]=\frac{((1+\hat{\varepsilon})(3 X-2))^{2}}{16 X^{2}}, \\
E\left[\pi_{m}^{I *} \mid \varepsilon=\hat{\varepsilon}\right]=\frac{((1+\hat{\varepsilon})(2-X))^{2}}{8 X} .
\end{gathered}
$$

The unconditional expected profits of the 3PP, the retailer and the manufacturer are:

$$
\begin{gathered}
E\left[\pi_{p}\right]^{I *}=E\left[E\left[\pi_{p}^{I *} \mid \varepsilon=\hat{\varepsilon}\right]\right]=\frac{\left(\xi^{2}+6 \xi+3\right)(1-X)(3 X-2)(X+2)}{48 X^{2}}-F, \\
E\left[\pi_{r}\right]^{I *}=E\left[E\left[\pi_{r}^{I *} \mid \varepsilon=\hat{\varepsilon}\right]\right]=\frac{(3 X-2)^{2}\left(4 \xi^{2}+6 \xi+3\right)}{48 X^{2}} \\
E\left[\pi_{m}\right]^{I *}=E\left[E\left[\pi_{m}^{I *} \mid \varepsilon=\hat{\varepsilon}\right]\right]=\frac{(2-X)^{2}\left(4 \xi^{2}+6 \xi+3\right)}{24 X}
\end{gathered}
$$

Thus, the unconditional expected profit of the supply chain is:

$$
E\left[\pi_{c}^{I *}\right]=\frac{3(1+\xi)^{2}\left(4-X^{2}\right)+\left((3 X-2)^{2}+2 X(X-2)^{2}\right) \xi^{2}}{48 X}-\frac{(1-X)\left(3 X^{2}+4 X-4\right) \xi^{2}}{24 X^{2}}-F .
$$

Overall, the equilibrium is concluded in Table 4.

\section{Proof of Propositions 1-2}

The results can be straightforwardly obtained by comparing the equilibrium with and without the 3PP, the details are omitted.

\section{Proof of Propositions 3-4}

The results can be straightforwardly obtained by comparing the equilibrium in the noninformation sharing case and the information sharing case, the details are omitted.

\section{References}

Adida, E., Bakshi, N., \& DeMiguel, V. (2016). Supplier capacity and intermediary profits: Can less be more? Production and Operations Management, 25(4), 630-646. 
Belavina, E., \& Girotra, K. (2012). The relational advantages of intermediation. Management Science, 58(9), 1614-1631.

Chan, H. L., Shen, B., \& Cai, Y. (2017). Quick response strategy with cleaner technology in a supply chain: coordination and win-win situation analysis. International Journal of Production Research, 56(10), 3397-3408.

Chen, X., Cai, G., \& Song, J. S. (2018). The cash flow advantages of 3PLs as supply chain orchestrators. Manufacturing \& Service Operations Management, 21(2), 435-451.

Chen, X., \& Wang, A. (2012). Trade credit contract with limited liability in the supply chain with budget constraints. Annals of Operations Research, 196(1), 153-165.

Chiu, C. H., Choi, T. M., Dai, X., Shen, B., \& Zheng, J. H. (2018). Optimal advertising budget allocation in luxury fashion markets with social influences: A mean-variance analysis. Production and Operations Management, 27(8), 1611-1629.

Choi, H. C. P., Blocher, J. D., \& Gavirneni, S. (2008). Value of sharing production yield information in a serial supply chain. Production and Operation Management, 17(6), 614-625.

Choi, S., \& Fredj, K. (2013). Pricing competition and store competition: Store brands vs. national brand. European Journal of Opration Research, 225(1), 166-178.

Choi, T. M., Ma, C., Shen, B., \& Sun, Q. (2018). Optimal pricing in mass customization supply chains with risk-averse agents and retail competition. Omega, 88, 150-161.

Dong, C. W., Liu, Q. Y., \& Shen, B. (2019). To be or not to be green? Strategic investment for green product development in a supply chain. Transportation Research Part E: Logistics and Transportation Review, $131,193-227$.

Govindan, K., Kadziński, M., Ehling, R., \& Miebs, G. (2018). Selection of a sustainable third-party reverse logistics provider based on the robustness analysis of an outranking graph kernel conducted with ELECTRE I and SMAA. Omega, 85, 1-15.

Guo, L., \& Zhao, Y. (2009). Voluntary quality disclosure and market interaction. Marketing Science, 28(3), $488-501$.

Ha, A., Long, X., \& Nasiry, J. (2016). Quality in supply chain encroachment. Manufacturing \& Service Operations Management, 18(2), 280-298.

Ha, A. Y., \& Tong, S. (2008). Contracting and information sharing under supply chain competition. Management Science, 54(4), 701-715.

Huang, S., Guan, X., \& Chen, Y. J. (2018). Retailer information sharing with supplier encroachment. Production and Operations Management, 27(6), 1133-1147.

Kannan, D., Garg, K., Jha, P. C., \& Diabat, A. (2017). Integrating disassembly line balancing in the planning of a reverse logistics network from the perspective of a third party provider. Annals of Operations Research, 253(1), 353-376.

Katehakis, M. N., Melamed, B., \& Shi, J. (2016). Cash-flow based dynamic inventory management. Production and Operations Management, 25(9), 1558-1575.

Li, G., Wu, H., \& Xiao, S. (2019). Financing strategies for a capital-constrained manufacturer in a dual-channel supply chain. International Transactions in Operational Research, 33, 153-164.

Shamir, N. (2012). Strategic information sharing between competing retailers in a supply chain with endogenous wholesale price. International Journal of Production Economics, 136(2), 352-365.

Shamir, N., \& Shin, H. (2016). Public forecast information sharing in a market with competing supply chains. Management Science, 62(10), 2994-3022.

Shen, B., Choi, T. M., \& Chan, H. L. (2019a). Selling green first or not? A bayesian analysis with service levels and environmental impact considerations in the big data era. Technological Forecasting and Social Change, 144, 412-420.

Shen, B., Choi, T. M., \& Minner, S. (2019b). A review on supply chain contracting with information considerations: information updating and information asymmetry. International Journal of Production Research, 57(15-16), 4898-4936.

Shen, B., Zhu, C., Li, Q., \& Wang, X. (2020). Green technology adoption in textiles and apparel supply chains with environmental taxes. International Journal of Production Research. https://doi.org/10.1080/00207 543.2020 .1758354$.

Shi, X., \& Shen, B. (2019). Product upgrading or not: R\&D tax credit, consumer switch and information updating. International Journal of Production Economics, 213, 13-22.

Singh, R. K., Gunasekaran, A., \& Kumar, P. (2018). Third party logistics (3pl) selection for cold chain management: A fuzzy ahp and fuzzy topsis approach. Annals of Operations Research, 267(1-2), 531-553.

Wu, S. D. (2004). Supply chain intermediation: A bargaining theoretic framework (pp. 67-115). Berlin: Handbook of Quantitative Supply Chain Analysis. Springer.

Wuttke, D. A., Blome, C., Sebastian Heese, H., \& Protopappa-Sieke, M. (2016). Supply chain finance: Optimal introduction and adoption decisions. International Journal of Production Economics, 178, 72-81. 
Yan, N., He, X., \& Liu, Y. (2018). Financing the capital-constrained supply chain with loss aversion: Supplier finance vs. supplier investment. Omega, 88, 162-178.

Yang, Z., \& Babich, V. (2014). Does a procurement service provider generate value for the buyer through information about supply risks? Management Science, 61(5), 979-998.

Zhang, T., Choi, T. M., \& Zhu, X. (2018). Optimal green product's pricing and level of sustainability in supply chains: Effects of information and coordination. Annals of Operations Research. https://doi.org/10.1007/ s10479-018-3084-8.

Zhen, X., Shi, D., Li, Y., \& Zhang, C. (2020). Manufacturer's financing strategy in a dual-channel supply chain: Third-party platform, bank and retailer credit financing. Transportation Research Part E. https://doi. org/10.1016/j.tre.2019.101820.

Publisher's Note Springer Nature remains neutral with regard to jurisdictional claims in published maps and institutional affiliations. 